\title{
Correction to: Pigment dispersion syndrome and pigmentary glaucoma: a review and update
}

\author{
Gianluca Scuderi - Maria Teresa Contestabile - Luca Scuderi • \\ Aloisa Librando $\cdot$ Vito Fenicia $\cdot$ Siavash Rahimi
}

Published online: 6 June 2019

(C) Springer Nature B.V. 2019

\section{Correction to: Int Ophthalmol \\ https://doi.org/10.1007/s10792-018-0938-7}

In the original publication, introduction section under Abstract was published incorrectly. The correct version is given below.

Introduction Pigment dispersion syndrome (PDS) is a condition where anomalous iridozonular contact leads

The original article can be found online at https://doi.org/10.1007/s10792-018-0938-7.

G. Scuderi - M. T. Contestabile · V. Fenicia Ophthalmology Unit, St. Andrea Hospital, Faculty of Medicine and Psychology, NESMOS Department, University of Rome "Sapienza", Rome, Italy e-mail: gianluca.scuderi@uniroma1.it

M. T. Contestabile

e-mail: mariateresa.contestabile@uniroma1.it

V. Fenicia

e-mail: vito.fen@gmail.it

L. Scuderi $(\bowtie) \cdot$ A. Librando

Ophthalmology Unit, Azienda Ospedaliera Universitaria Policlinico Umberto I, University of Rome "Sapienza", Viale del Policlinico 155, Rome 00161, Italy

e-mail: lucascuderi@hotmail.com to pigment dispersion throughout the anterior segment and the released pigment is abnormally deposited on various ocular structures.

The original article has been corrected.

Publisher's Note Springer Nature remains neutral with regard to jurisdictional claims in published maps and institutional affiliations. 